\title{
EL MIEDO, EL OTRO, EL FIN. VIOLENCIAS LEGALES, VIOLENCIAS LETALES ${ }^{1}$
}

\author{
PATXI LANCEROS \\ Universidad de Deusto (Bilbao) \\ «...quod sumus nos, nati in saeculis desertis». \\ Tertuliano
}

\begin{abstract}
RESUMEN: En este artículo se pretende dar cuenta de las dificultades por las que atraviesan las democracias occidentales en la época de la globalización, sometidas como están al estrés que provoca la doble presión de dos factores: un miedo creciente, cuyas causas radican en la confluencia del capitalismo financiero y la hegemonía liberal, con el saldo de inseguridad que provocan; y la confrontación, que cada vez toma formas más preocupantes, con diversos tipos y grados de alteridad: masas humanas desplazadas o expulsadas de sus lugares de residencia y acosadas por motivos económicos, culturales o políticos que no encuentran cobijo en ningún lugar sino que reciben hostilidad o desprecio. PALABRAS CLAVE: democracia, violencia, inmigración, miedo, xenofobia.
\end{abstract}

Fear, the other, the end. Legal violences, deadly violences

ABSTRACT: This paper aims to give an account of the difficulties that western democracies are going through in this globalization's time, undergoing the stress that causes the double pressure of two factors: a growing fear which causes lie on the confluence of financial capitalism and liberal hegemony (with the output of insecurity they both cause), and the confrontation, that increasingly adopts more worrying forms, with diverse kind and grades or otherness: human masses of displaced persons or expulsed of their residences and hounded by economic, cultural or political motivations, that do not find refuge nowhere and becoming hostility and disdain.

KEY WORDS: democracy, violence, immigration, fear, xenophobia.

\section{IN(TRO)DUCCIÓN}

En condiciones normales se sabe, con muy escaso margen de error, cuál es el poder capaz de organizar la sociedad. Capaz de dotar a la sociedad de una estructura perceptible, o de proponer, e incluso de imponer, metas y objetivos. En esas condiciones el poder en cuestión se legitima. Poco importa que a lo largo de la historia se hayan sucedido poderes, en su momento legítimos, que hoy no gozarían de salvoconducto; o que serían contemplados, con razón, como ejercicios de imposición más o menos violenta, más o menos tiránica.

1 El presente texto se enmarca dentro del marco del Proyecto de Investigación Poder Público y Empresa en un contexto multinivel y transnacional (Gobierno Vasco IT607-13 / Deusto R2013) de la Facultad de Derecho de la Universidad de Deusto. 
Puede ser una institución que gestiona ideología, o una que acumula el poder militar -la fuerza-; puede ser una institución que decide sobre los recursos o una que administra las necesidades y su satisfacción. Puede ser un cuerpo institucional que garantiza el cumplimiento estricto de una ley racional que se impone sobre todas las instancias en potencial conflicto. Poderes, se ve, diferentes en cuanto a sus pretensiones, sus fundamentos o sus técnicas. Poderes que, en condiciones normales, son capaces de producir consenso: voluntario en muchas ocasiones, obligatorio en otras, forzado en algunas².

En condiciones normales. Lo que ocurre es que en la situación de desgobierno y descontrol que hoy, perceptible y tenazmente, se va apoderando del mundo, la condición de normalidad parece sustituida por un prolongado estado de excepción ${ }^{3}$.

No se puede saber a ciencia cierta si los dolores que afligen al mundo son dolores de parto o estertores de muerte. La magna historia es el rastro de escombros y ruinas al que algunos optimistas (y algunos nostálgicos) denominan progreso. La célebre imagen es de W. Benjamin, basada, parece, en la obstinada contemplación de un atónito ángel esquemáticamente dibujado por Paul Klee ${ }^{4}$. Arrastrado por el vendaval de la historia y con la mirada vuelta hacia atrás - hacia el pasado- el ángel contempla la estela de la destrucción.

El presente podría ser proclive, lo veremos, a interpretaciones apocalípticas (consecuencia, seguramente, de frustraciones reiteradas). Hemos superado con creces el cambio de milenio; pero algunas sensibilidades póstumas se aficionan todavía a proponer epitafios y a entonar letanías.

No parece, sin embargo, que la sensibilidad general, indecisamente posmoderna y decididamente atareada en la cotidiana tarea de la supervivencia, se sienta concernida por los temblores milenarios, aunque sí por una ineludible evidencia de inseguridad: evidencia de que algo, o todo, falta o falla; lo prometido, lo esperado, lo calculado, lo previsto. Inseguridad, pues; y su casi inevitable corolario: el miedo. La bisagra del primer milenio sacudió al mundo —es decir, a una limitada región de Eurasia- con la urgencia de la salvación. El umbral

2 Una advertencia sobre esa palabra "consenso» (y otras de intención y propósito similares: acuerdo, pacto...), que parece requerir universal e incondicional aquiescencia. Las alusiones al consenso no se confunden aquí, espero, con las ilusiones del consenso. Se puede anticipar como regla general y sin mayores precisiones que todos los consensos encubren conflictos, que todos los consensos someten a alguien o sacrifican algo. Se aludirá aquí, pues, a consensos fácticos; que, como las leyes por ejemplo, son objeto de observación, e incluso de observancia. Pero que también son y han de ser, como las leyes por supuesto, objeto de crítica y deconstrucción, e incluso de disidencia. ¡Hay más cosas en el cielo y la tierra de las que se sueñan en cada consenso!, podría exclamarse, recordando las palabras que Hamlet dirige a Horacio. Los sueños, por cierto, pueden ser auténticas pesadillas.

3 Algo se dirá más adelante sobre esta figura, la del «estado de excepción», que es uno de los elementos problemáticos del texto.

4 La referencia es, obviamente, a las llamadas «tesis» Sobre el concepto de historia. Ahora en Benjamin, W.: Obras, libroI / vol. 2, Abada editores, Madrid, 2008, pp. 303 ss. 
del segundo milenio no nos ha sugerido epopeyas: ni nos amenaza el terror, ni nos impulsa la esperanza. Nos somete el miedo.

Convivimos con los innumerables desgarros que constituyen el mundo. Desgarros incesantes, ajenos a la contundencia de los guarismos y a la convencional dictadura del calendario. Desgarros que acumulan escombro y ruina, como monumentos de los que la historia apenas quiere, o apenas consiente, memoria.

Quizá, es cierto, la humanidad haya vivido siempre en estado de indigencia, quizá haya asumido siempre una cierta minoría de edad o una impotencia cierta. Quizá haya tenido siempre la sensación de que algo, incomprensible, gobierna (o desgobierna) por encima de opciones y decisiones. La impotencia del humano ha sido explicada - y ha sido implicada- por los caprichos de los dioses, o por los inescrutables designios del Dios uno y único, o por la astucia de la razón, o por los múltiples avatares de lo diabólico —-(in)constante en su acción-.

Hoy, esos referentes han perdido parte de su pretérita autoridad: acosados por la idea de que el humano podría, a través de la planificación y el cálculo, someter la contingencia y convertir el caos en orden. Idea moderna, muy moderna, que también, sospecho, ha dimitido 5 .

\section{EL MIEDO}

La sensación que en el momento actual nos imponen el tiempo y las costumbres es de ingobernable complejidad ${ }^{6}$. Complejidad que afecta a todos los ámbitos y dimensiones de los afectos, del pensamiento y de la acción. Que se expresa en lo privado y en lo público, en las relaciones afectivas, sociales, económicas y políticas, en las relaciones con la naturaleza herida o con los dioses: que retornan saturados de orgullo, furia y majestad ${ }^{7}$.

No es extraño que en los últimos años del (pasado) siglo, se impusiera en las ciencias humanas y sociales el concepto de riesgo: más como denominación de un problema que como pauta de una solución. El riesgo ha permitido a Ulrich Beck hablar de la sociedad y de la economía, de la ecología y del «normal caos del amor»; le ha permitido remitir la época, si no a la normalidad del caos, sí a

\footnotetext{
5 Sobre esa (in)voluntaria dimisión o sobre el forzado cese trata, en parte, este desmayado ensayo. Sobre la in/quietud que produce, sobre la enfermedad (infirmitas) que provoca.

6 Determinadas direcciones sociológicas de la teoría de sistemas (preciso es invocar el nombre de Niklas Luhmann y su vasta obra) así como ese campo de investigación orgullosamente autodenominado "Ciencias de la complejidad» ratificarían, si falta hiciera, la mencionada condición epocal. De Luhmann ha de considerarse al menos su ciclopeo trabajo Die Gesellschaft der Gesellschaft, Suhrkamp, Franfurkt a.M., 1998.

7 De forma escasamente encubierta la frase (tanto el diagnóstico como la metáfora) evoca y envía a otra, famosa, de Max Weber.
} 
la convivencia habitual con la incertidumbre. Y Beck no es, evidentemente, el único que indaga en esa dirección; sí, tal vez, el más conocido8.

Participo, humildemente, de la sospecha de que el proceso evolutivo ha generado más complejidad de la que el mero humano es capaz de gobernar. $\mathrm{O}$ en la sospecha de que hoy es imposible —o al menos improbable- hacerse cargo de las consecuencias no deseadas de cada acción: o de las consecuencias de las consecuencias. Esa sospecha no conduce a la decepción, ni a la deserción, ni a la parálisis. Sólo a la cautela. A pensar que cada solución puede generar mayores problemas; o que el problema puede ser una aceptable, y provisional, solución. O que en el peligro, como escribió Hölderlin, crece también lo que salva. Por desgracia, o por supuesto - pero esa no era ni la tesitura ni la preocupación del enorme poeta cuando escribía, una y otra vez, Patmos-, también, o sobre todo, lo contrario es cierto.

Asumamos la hipótesis de que las culturas — todas las culturas- son, básicamente, grandes mecanismos proveedores de seguridad. De hecho, la actividad sociocultural ininterrumpida y masiva, la actividad apenas perceptible, por silenciosa y discreta, no es la producción de excepciones sino la reproducción de rutinas. Todas las esferas que interactúan en la compleja vida colectiva, todas las instituciones, son aparatos de organización y control del espacio y del tiempo, aparatos ajustados para reducir el riesgo y reproducir la norma.

Desde el mito y la magia hasta la tecnología y los complicados códigos legales que hoy (des)organizan la convivencia, la especie humana ha ensayado multitud de formas de autorreproducción controlada. Quizá nuestra sociedad, nuestra cultura, haya alcanzado, en algún momento que amenaza con convertirse en pretérito (imperfecto) un mayor refinamiento: la prolongada escolarización obligatoria, los mecanismos de gestión del trabajo y del ocio, la seguridad social, los planes de ahorro y de pensiones, los contratos y los créditos, son (aunque tan vez sea más correcto escribir eran) complicados mecanismos para asegurar el orden, para dar a la vida —individual y colectiva - apariencia de cauce y curso.

El acontecimiento es lo extraño (no necesariamente hostil), es lo que irrumpe e interrumpe, lo que cae fuera de las clasificaciones habituales. El acontecimiento es lo que suspende el juicio o lo confunde: precisamente porque no hay esquema predispuesto para procesar esa aparición espectral o siniestra.

Sobrecogidos por el acontecimiento, atrapados por él, nuestros hábitos se desmoronan: y no hay palabras. O las palabras toman forma de interjección. Los discursos, que aparentemente dan razones, son, en realidad, largas

8 De U. BЕск, la obra de referencia para el tema que nos ocupa es: Risikogesellchaft. Auf dem Weg in eine andere Moderne. Suhrkamp, Frankfurt a.M. 1986. Pero también es preciso considerar, al menos: Gegengifte. Die organisierte Unverantwortlichkeit, Suhrkamp, Frankfurt a.M, 1988 y Politik in der Risikogesellschaft. Suhrkamp, Frankfurt a.M, 1991. Y es esencial la obra del ya citado Niklas Luhmann: Sociología del riesgo, Universidad Iberoamericana, México D.F., 2006, así como también, del mismo autor: Die Politik der Gesellchaft, Suhrkamp, Frankfurt a.M., 2000 o Macht im System, Suhrkamp, Frankfurt a.M., 2013. 
interjecciones a las que se priva de los convencionales signos de admiración; o, en el mejor de los casos, son prolongadas confesiones de estupor.

Ya desde sus primeras reflexiones sobre arte o estética, pero sobre todo en las últimas, Kant rescató y reactivó una vieja categoría que, si no explica la irrupción de lo inexplicable al menos designa el ámbito en el que se congela nuestro estupor: la categoría de lo sublime. Quizá las posibilidades de este idiosincrático concepto no hayan sido suficientemente exploradas fuera de la teoría del arte. Quizá esa categoría pueda ser el torrente - no el cauce- de nuestra impotencia. Lo sublime terrorífico: que no es la única forma de aparición de lo sublime, pero es la que hoy se impone ${ }^{9}$. Sea en la forma de macroatentado terrorista, de desmoronamiento económico, de caos ecológico o de terremoto migratorio.

En los países occidentales, que tienen buenos motivos y serias razones para ser considerados — todavía- como los más afortunados del planeta ${ }^{10}$, parece que antaño regía un consenso democrático basado en el estado de derecho, el imperio de la ley y en un implícito contrato social capaz de contener posibles perversiones: tanto las tentaciones de la política de derivar hacia la tiranía, las del ejército de imponer la fuerza, las del mercado y su ética de la ambición desmedida o las de ciertas instancias ideológicas que quieren, si pueden, conformar el pensamiento y determinar la cultura.

Esa era, más o menos, la figura - y el compromiso- del llamado «estado democrático y social de derecho». Que se ve suplantado hoy por un vago consenso democrático que cada vez da más muestras de fatiga. Y que, dramáticamente, escenifica su impotencia, su rendición —incondicional— ante poderes, fuerzas e instituciones que no son capaces de organizar la sociedad, pero sí de desorganizarla hasta niveles de riesgo sumo; hasta avistar el peligro de la descomposición. O hasta producir, contener y expulsar terribles cantidades de violencia, muchas veces legal; todas, letal.

Una sociedad desorganizada es una sociedad inerte, es una sociedad inerme. $\mathrm{Y}$ una sociedad que se tiene que someter a imperativos que, acaso, ni entiende ni comparte. Las medidas que hoy toman los gobiernos para, se dice, sortear

9 Queda(ría)n a su lado otros modos del inexplicable acontecer: lo noble, lo magnífico. Y también es cierto que tal vez sea un poco injusto afirmar sin cautelas que las posibilidades de la categoría de lo sublime no han sido suficientemente exploradas. Los trabajos sobre la Kritik der Urteilskraft, de 1790 (también los referidos a las Beobachtungen über das Gefühl des Schönen und Erhabenen, de 1764), son cuantiosos, y de indudable calidad. Para lo que aquí interesa es preciso citar: Lyotard, J. F., Lo inhumano. Charlas sobre el tiempo, Manantial, Buenos Aires, 1999; Lyotard, J. F., Leçons sur l'Analitique du sublime, Galilée, Paris, 1991; VV.AA., Du Sublime, Belin, Paris, 1998; CeSARINI, L. M., Le sublime anomique. Le renversement de l'histoire de Kant a Lyotard, L'Harmattan, Paris, 2008; Hernámdez Sánchez, D., La comedia de lo sublime, Quálea Editorial, Torrelavega, 2009.

10 Renunciamos aquí a glosar las diferentes condiciones, las diferentes causas, que concurren en la erección de tal fortuna: naturales e históricas, económicas y políticas, endógenas y exógenas...decentes e indecentes. 
la llamada crisis son un ejemplo de decisiones sobrevenidas ante las que no se aprecia reacción social significativa ${ }^{11}$.

A falta de compromiso viable, vale la parodia; o vale - porque no hay másla reacción de distancia —ironía- frente a todas las instituciones. Algunas de las cuales, tal vez inconscientemente, muestran en público su incapacidad, su trivialidad. Hacen espectáculo de sí mismas y hacen espectáculo, no sólo para, sino de la sociedad.

Si es triste observar la capitulación de los actores políticos frente al poder disgregador del mercado, más triste es ver la parodia, el espectáculo de esos mismos actores que exhiben obscenamente su falta de fundamento, de dignidad y cultura; que dimiten incluso del sentido común. O que contemplan con desidia el deterioro generalizado. Un deterioro histórico al que casi se otorga «carta de naturaleza».

Ante ese espectáculo de una sociedad sometida, la distancia -ironía ${ }^{12}$ - es casi una obligación: por dignidad. Y es, también, una muestra más —acaso desesperada, acaso lúcida- de impotencia.

El buen funcionamiento del sistema democrático, o la razonable salud de las instituciones que lo sustentan, exige ciertas condiciones o requisitos, tanto de índole material como formal. Es preciso reparar en ello porque parece darse por supuesto que la democracia constitucional es el régimen «normal» de convivencia cívica, que se establece "por defecto», o que una vez conquistado no puede ser abandonado. Y esa convicción, tan inconsciente como extendida, es harto peligrosa, por cuanto promueve una indolencia generalizada que, a la postre, puede resultar fatal.

Se olvida, o se quiere ignorar, que las democracias son regímenes de gobierno con escaso espesor histórico; que sólo recientemente - y en algunos casaos muy recientemente- se han convertido en hegemónicas en algunas partes del mundo en las que parecen imponerse sin aparente discusión y sin aparente alternativa. Precisamente esa hegemonía fue la que hace algunos años llevó a algún intelectual eufórico a proclamar un presunto fin de la historia cuyo signo sería, precisamente, la expansión del modelo democrático liberal ${ }^{13}$. La utopía al fin lograda. Y, consecuentemente, la desactivación, la devastación del pensamiento utópico.

Frente a esa euforia es más bien oportuno pensar, o recordar, que la democracia es un régimen complicado y contingente, que no responde a ninguna

11 Reacción social, o política, que trascienda, se entiende, la frustración. O la más popular «indignación».

12 Se puede entender que el par de párrafos apologéticos tratan de justificar alguno de los pasajes de este ensayo. Y es cierto. Pero también lo es que tratan de legitimar la función y el alcance de esa figura no sólo retórica, la ironía, de larga y venerable historia.

13 La referencia es, obviamente, a Francis Fukuyama y, concretamente, a su libro El fin de la historia y el último hombre, planeta, Barcelona, 1992; presentado en la portada como «La interpretación más audaz y brillante de la historia presente y futura de la Humanidad». Nada menos. 
necesidad de la naturaleza o de la historia, que no está inscrito en ningún código genético. Y es conveniente pensar que, de la misma forma que la democracia se hizo posible a través de ciertos procesos y determinados progresos, la misma democracia se puede deteriorar, hasta hacerse irreconocible, en virtud $-\mathrm{O}$ vicio- de otros procesos a los que no cabe llamar progresos. Distopía (pre)visible.

Conviene, por ello, tener siempre en cuenta el carácter condicional, y fuertemente condicionado, de ese régimen de gobierno. Una de las condiciones que lo sustentan, la que está a la base de su trama institucional y garantiza su legitimidad, se articula sobre una palabra de la que frecuentemente se abusa: representación ${ }^{14}$. Las instituciones democráticas son, efectivamente, instituciones representativas. Esa característica las particulariza y las diferencia.

Ahora bien ¿cómo se cumple la lógica de la representación en sociedades democráticas? Se suele decir, y hasta cierto punto es verdad, que el parlamento representa a la sociedad, también que representa al pueblo, o a la nación. Pero sociedad, pueblo y nación son tres conceptos con diferente significado, con diferente alcance y con diferente historia. Cada uno de ellos produce - permite o exige- un esquema distinto de representación.

La sociedad, por ejemplo, es irrepresentable como unidad: porque carece de ella. O sólo se presenta como unidad cuando se vuelcan sobre ella los criterios, que en principio le son ajenos, del pueblo o la nación. Si de estos últimos - pueblo y nación- se puede proponer una definición presuntamente coherente y unitaria (y por ello proclive a exclusiones implícitas o explícitas), la sociedad no admite tal tipo de definición. Pues sociedad es, ante todo y sobre todo, relación; es, ante todo y sobre todo, comunicación (y, por eso mismo, diferencia, dispersión... conflicto).

Podrá haber mil discusiones al respecto de «lo» que constituye el pueblo, o de cuál es la «esencia» de la nación. No habrá tantas discusiones —ni de tan hondo calado metafísico- al respecto de la sociedad. Pues la sociedad no tiene esencia. La relación y la comunicación (en sus muy diversos modos de efectuarse) constituyen su mera existencia.

Cualquier individuo, o grupo, que entra en relación — del tipo que sea y durante el tiempo que sea- pasa a formar parte de ese sistema de consensos inestables y de conflictos incesantes que es la sociedad. Pasa a formar parte de ese conglomerado que se caracteriza por la movilidad. Y por la irrepresentabilidad. $\mathrm{O}$, más exactamente, por ser irrepresentable como unidad y unanimidad, como homogeneidad.

14 Para la historia de la palabra y sus distintos alcances, es conveniente leer, al menos, la entrada "Repräsentation», firmada por Adalbert Podlech, en OTTO BRUNNER, WerneR Conze, Reinhart Koselleck, Geschichtliche Grundbegriffe, Klett-Cotta, Stuttgart, 2004 (Studienausgabe), Band 5, pp. 509-548. También el libro de BRuno Accarino, Representación, Nueva Visión, Buenos Aires, 2003. Y sobre todo el impecable trabajo de Hasso Hofmann, Repräsentation. Studien zur Wort- und Begriffsgeschichte von der Antike bis ins 19. Jahrhundert, Duncker \& Humblot, Berlin, 2003, (4ª ed.). 
El reto de las instituciones democráticas, que han de adaptarse cada vez más y cada vez de forma más acelerada a una sociedad crecientemente compleja, es, precisamente, representar lo irrepresentable. Es decir, olvidar las ficciones de (la) unidad, las nostalgias de (la) homogeneidad.

Hubo tiempos, sin duda, en los que los ámbitos de relación social casi coincidían con espacios culturales y políticos cerrados. Ya no es así. Hoy la sociedad desborda cualquier límite. Hoy la sociedad, relación y comunicación, salta cualquier barrera. Y es esa sociedad indócil, fascinante y conflictiva, lo que hay que (ir)representar. Sin someter.

Queda para la teoría política - habitualmente desencantada o escépticadeliberar sobre el verdadero sentido de la democracia (si es que hay tal ${ }^{15}$ ): tanto de la palabra como de las realizaciones concretas que en su nombre se han hecho a lo largo del tiempo y en multitud de espacios. Queda para la teoría política deliberar sobre el démos, sobre el pueblo (así se suele traducir la palabra griega), y sobre el krátos: el poder o el gobierno, o la fuerza, o la victoria. Y, sin duda, sobre el poder y el gobierno del pueblo (por el pueblo y para el pueblo: según célebre definición de genuino sabor americano).

Reflexión pendiente, acaso infinita, sobre una "democracia por venir», como le gustaba decir al difunto Jacques Derrida ${ }^{16}$; sobre una eventual realización de la democracia sin exclusiones, sin grupos de poder o de presión. Una democracia pendiente, siempre pendiente (pero...¿pendiente de qué?), que opera como criterio regulativo de la democracia presente; o de la democracia realmente existente, cuya perfectibilidad salta a la vista ¿Genuina pro-posición de la genuina utopía -si, de nuevo, hubiere tal?

Esa tarea que queda para la teoría política no obsta a la hora de evidenciar el código de funcionamiento de la - presente o presunta- democracia parlamentaria. Sobre todo en un momento, como el actual, en el que ésta se pone en cuestión, desde muy diferentes ámbitos y en muy distintos foros.

El código de la democracia parlamentaria es sencillo: consiste en la polaridad gobierno/oposición ${ }^{17}$. Lo que quiere decir, de entrada, que la democracia - esta democracia - no es exactamente el gobierno del pueblo sino la representación - parlamentaria- de conflictos de interés, de afecto, de identidad. Representación de convergencias y divergencias, de consensos y conflictos, que encuentran su lugar en el parlamento: y, a partir de él, en el gobierno y en la oposición.

15 O si es que hay (o hubiera) tales: verdadero, sentido y democracia.

16 Toda la obra del gran filósofo francés es pertinente para lo que aquí se enuncia. Véanse al menos: Derrida, J., El otro cabo. La democracia para otro día, Ediciones del Serbal, Barcelona, 1992; Fuerza de ley. El «fundamento místico» de la autoridad, Tecnos, Madrid, 2002; Espectros de Marx. El estado de la deuda, el trabajo del duelo y la nueva internacional, Trotta, Madrid, 1995; Políticas de la amistad, Trotta, Madrid, 1998; Canallas. Dos ensayos sobre la razón, Trotta, Madrid, 2005.

17 Sobre el particular se ha expresado con notable éxito y sobresaliente insistencia el doblemente citado Niklas Luhmann. 
El funcionamiento democrático implica asumir esa idea básica, sencilla: el pueblo tampoco es representado (ni representable) como unidad o totalidad, no es representado ni representable como comunidad homogénea, como esencia inalterable siempre idéntica a sí misma. De lo contrario no hay democracia parlamentaria posible.

Fue precisamente el jurista -(in)oportuna u ocasionalmente nazi- Carl Schmitt el que denunció la representación parlamentaria, liberal o republicana, en virtud de una representación pura y genuinamente existencial: representación no sólo (aunque también) de la idea o del concepto, de la esencia de un pueblo, sino de la vida del pueblo concebido como "comunidad de amigos» que se enfrentan - a muerte, en el extremo- a un enemigo común ${ }^{18}$. Representación mítica y mística de un pueblo inexistente, o de una colectividad que se construye a base de plurales violencias, de drásticas amputaciónes, reales e imaginarias: idea e ideal de un gobierno sin oposición.

Frente a esa continuidad mística entre el pueblo y «su» gobierno, frente a la inmediatez que identifica al uno con el otro, la representación parlamentaria carece de legitimación existencial: su única legitimación es lingüística y matemática. Y enseña que para la constitución de mayorías de gobierno lo que hace falta es saber sumar. Sumar: esa operación tan sencilla que se enseña en la escuela elemental; pero que en el ámbito de la política resulta complicada para muchos e imposible para algunos. Y que, así y todo, no garantiza el ejercicio de una democracia plena. $\mathrm{O}$, simplemente, de una política digna. Porque, en el extremo, de lo que se trata es de algo que no resuelve la aritmética sin el concurso de la dialéctica: de sumar sin restar y de multiplicar sin dividir; y todo ello en ausencia de unidad (e incluso en ausencia de criterio y escala de medida).

Lo que da valor y sentido (o lo que meramente permite realizar su función) a la democracia parlamentaria, lo que constituye su misterio, o su mera dificultad, es la «parte diversa» derivada de la suma: que no (se) resta, que no se excluye; o que se incluye como oposición. ¿Por qué misterio? Porque el pueblo, que no está en ningún sitio, está a la vez en el gobierno y en la oposición. Y porque para ejercer eficazmente el cometido que la mera democracia parlamentaria exige al uno y a la otra son necesarios, obviamente, ambos. Incluidos sin resto, sin resta. El resto, lo excluido, está — se verá enseguida- en otra parte. Sobre todo en circunstacias en las que la incertidumbre y el miedo hacen

18 De Schmitt ha de verse, para esta cuestión: El nomos de la tierra en el Derecho de Gentes del Jus Publicum Europaeum, Centro de Estudios Constitucionales, Madrid, 1979; Verfassungsrechtliche Aufsätze aus den Jahren 1924-1954, Duncker \& Humblot, Berlin, 2003, pp. 489 ss.; Staat, Grossraum, Nomos. Arbeiten aus den Jahren 1916-1969, Duncker \& Humblot, Berlin, 1995, pp. 573 ss; Positionen und Begriffe im Kampf mit Weimar-GenfVersailles 1923-1939, Duncker \& Humblot, Berlin, 1988, pp. 335 ss. Al respecto, cf. Galli, C., Spazi Politici. L'etá moderna e l'etá globale, Il Mulino, Bologna, 2001; Marramao, G., Pasaje a Occidente. Filosofía y globalización, Katz Editores, Buenos Aires, 2006; Navarrete Alonso, R.: Los tiempos del poder. Franz, Rosenzweig y Carl Schmitt (en prensa). 
de la suma una operación complicada y de la resta una violencia legal. Y, se ha anticipado, letal.

Se dice, y nada hay que objetar, que el miedo es libre. Nadie ha osado, sin embargo, afirmar que el miedo nos haga más libres: que el miedo como argumento sea un factor de libertad o liberación.

Más bien al contrario. Testimonios antiguos, no por ello menos venerables, e investigaciones modernas tienden a mostrar que el miedo altera hasta tal punto la vida pública (también la cotidiana vida doméstica, cabe añadir) que es el causante mayor de reacciones, frenéticas y fanáticas, que lindan con el caos, que disparan la violencia o que auguran el desastre ${ }^{19}$.

David Hume escribió que la primera página del libro de Tucídides (la Historia de la Guerra del Peloponeso) es, a la vez, la primera página de la historia universal. Tal vez se estime que la expresión es hiperbólica y el juicio extremo. Pero no se trata aquí de eso. Sí se trata de que para Tucídides, fino observador y gran analista, esa guerra, "la mayor que conocieron los griegos y aun los bárbaros», no se debió a causas "objetivas», a ambiciones económicas o políticas digamos, sino precisamente al miedo. El miedo al expansionismo ateniense, que provocó la reacción espartana y la escalada bélica. Esa habría sido la causa inmediata de una guerra que acabó con la época dorada de Grecia.

Páginas gloriosas ha dedicado al miedo Thomas Hobbes, uno de los más lúcidos pensadores políticos de la historia; y acaso uno de los más lúgubres ${ }^{20}$. El mutuo temor y el deseo, o la necesidad, de seguridad es lo que mueve a los hombres a entregarse, a rendirse, al poder omnímodo del Estado - hombre artificial, dios mortal-, sin cuya tutela, armada, la vida humana sería «solitaria, pobre, desagradable, brutal y corta»; como escribe, famosamente, en Leviatán ${ }^{21}$.

¿Testimonios y memoria de otra edad? ¿De tiempos en los que, efectivamente, el miedo estaba justificado porque no existían suficientes mecanismos de

19 Alguna nota clásica (Tucídides, Hobbes) se dará en breve. Pero hay que referir a: Canetti, E., Masa y poder, Debolsillo, Barcelona 2006, así como Apuntes (1 y 2), Debolsillo, Barcelona, 2008; Sofsky, W., Tratado sobre la violencia, Abada, Madrid, 2006 y Tiempos de horror. Amok, violencia, guerra, Siglo xxi, Madrid, 2004; Wieviorka, M., La violence, Hachette, Paris, 2005; Gros, F., États de violence. Essai sur la fin de la guerre, Gallimard, parís, 2006.

20 Hay que recordar el conocido episodio en el que Hobbes, en su Autobiografía en verso, se califica a sí mismo como hermano mellizo del miedo (que, a la vez, habría actuado como impulsor de su propio nacimiento): alertada de la inminente llegada de la Armada Invencible (vencida, sin embargo: aunque fuera por ciertos elementos), a la madrte de Thomas se le precipitó el parto; y dio a luz gemelos: «a mí mismo y al miedo al mismo tiempo».

${ }_{21}$ Resultado, pues, de la acumulación y de la transferencia de los miedos individuales, privados, el Estado hobbesiano (que muy posiblemente con-tiene - con-trae y con-lleva-el $A D N$ del Estado en todas sus fururas y quizá aún presentes versiones) tiene miedo. Y tal vez sólo eso tiene: miedo. Consecuentemente, da lo que tiene y tiene lo que da: miedo. No se trata, claro está, de la única forma de concebir el Estado. Pero no deja de ser inquietante, o meramente interesante, que en la génesis, obviamente moderna, del «más frío de los monstruos fríos» (Nietzsche) el miedo ocupe el lugar central. Y también periférico. 
seguridad, o porque la humanidad no había alcanzado una presunta «mayoría de edad»?

Apenas es sostenible el argumento. Apenas es pensable. La nuestra es la verdadera, la genuina edad de los miedos. Y los miedos son globales. Y son múltiples. Políticos y étnicos, ecológicos y sanitarios, migratorios y económicos. Pues la modernidad en su fase declinante unida al imparable proceso de globalización - a la creciente masificación de la movilidad y de los intercambios- produce fantasmas. Y los fantasmas, se sabe, provocan miedo. Tómese la palabra "fantasma» en un sentido riguroso; y serio. Dado que los fantasmas o espectros resultan eficaces, no se puede saldar la discusión a su respecto negando, sin más, su existencia. El fantasma de la alteridad amenazante, de la otredad que me reta o me niega, por ejemplo. $\mathrm{O}$ el fantasma de la filiación territorial, de la presunta naturalidad del territorio y las exigencias que comporta $^{22}$. Fantasmas que, toscamente invocados, citan a otro letal: el terror, el terrorismo; de estado o de partido, de iglesia o de mercado.

Miedos, miedos como argumento que se gestionan con eficacia. Y que provocan reacciones: demandas paranoicas de seguridad, blindaje de fronteras, xenofobias de varias intensidades.

Cabe mencionar como informado testimonio el libro de Zygmunt Bauman Miedo líquido ${ }^{23}$. Fiel a la metáfora de la liquidez que rige sus investigaciones sobre la sociedad contemporánea, el sociólogo polaco mostraba la facilidad con la que el pánico, multiforme, fluye a través de los medios de comunicación. Y mostraba el abismo al que se acerca una sociedad dominada por el miedo: pues tal vez el miedo, Hobbes lo sabía, es la forma más eficaz de dominio.

Quizá menos conocido, quizá más plástico, es el trabajo que en forma de documental dirigió para la BBC Adam Curtis, que antaño fuera profesor de Pensamiento Político en la Universidad de Oxford. Como todo en estos tiempos, el documental circula por la red. Se titula «El poder de las pesadillas» (The Power of Nightmares) y es un análisis logrado de la gestión política del miedo. Inocúlese el miedo suficiente durante el tiempo necesario en las dosis aconsejadas y se producirá una reacción colectiva que demandará seguridad a cualquier precio. Y cualquier precio parecerá escaso: se sacrificará un poco de libertad, bastante igualdad, y todo lo que haya que sacrificar.

Miedos no faltan, sobre todo en tiempos de crisis $^{24}$, para ofrecerse a una eficaz gestión: miedo a la pérdida de empleo, al descenso del nivel de vida, a

22 La literatura al respecto es tan inabarcable como de calidad. Véanse tan sólo dos excelentes compilaciones de Berding, H., Mythos und Nation, Suhrkamp, Frankfurt a.M., 1996; Nationales Bewusstsein und kollektive Identität, Suhrkamp, Frankfurt a.M., 1994.

${ }^{23}$ Es, evidentemente, tan sólo un ejemplo de la ingente investigación que hoy se hace - y se ha de hacer - al respecto del miedo como operador político; y no sólo político BaUman, Z., Miedo líquido. La sociedad contemporánea y sus temores, Paidós, Barcelona, 2007.

24 Que la palabra «crisis» sea la más adecuada para describir la actual situación, a pesar de la reiteración o precisamente por ella, es algo que he discutido en mi ensayo «Tras la modernidad. De la crisis a la intemperie», en: Cadahia, L. y Velasco, G. (eds.), Normalidad de la crisis/crisis de la normalidad, Katz, Buenos Aires y Madrid, 2012, pp. 81 ss. 
la inmigración, al inescrutable futuro. Miedo al enemigo declarado y miedo al enemigo potencial, miedo a la contingencia o a los insobornables elementos. O miedo a los semejantes: precisamente por serlo. La igualdad se convierte en amenaza. Y miedo al casi-semejante, al otro, al a-llegado: a sus intenciones, a sus necesidades, a sus miserias. No se trata aquí de los miedos provocados por la geopolítica y la geoestrategia, de esos miedos vinculados, por ejemplo, a atentados espectaculares. Se trata del miedo distribuido por el tejido social: de un miedo que se registra y se expone en gestos que parecen significar respeto, en tomas de postura que realmente son tomas de distancia, en muecas de desaprobación o rechazo, en silencios, o en la búsqueda de un lenguaje descomprometido, tendencialmente neutro, que se asocia con la "corrección política»: vericuetos en los que el cuerpo se disfraza o se transmuta, en los que el lenguaje se inhibe. Vericuetos en los que se imponen el disimulo y la máscara.

Seguiremos, parece, con el miedo a cuestas. Con los grandes miedos, los que impulsan a una entrega incondicional a un poder omnipotente (que no ha de ser necesariamente el del Estado; y que quizá lo sea cada vez menos). Y con los pequeños miedos; pequeños pero multiplicados: cada vecino o cada viandante, cada interlocutor, es un competidor virtual o real. Esos miedos no forman la musculosa figura presuntamente unitaria del Estado, tampoco la necesariamente múltiple de la Sociedad. Desintegran toda figura posible en un flujo de disimulos advertidos y consentidos. En una multitud de individuos que aman (o necesitan) la máscara: lo que no los hace necesariamente profundos.

Operador político de primera magnitud, el miedo - epidémico o endémico, incontenible - ha dejado de ser un «estado de excepción», una anomalía (si es que alguna vez lo fue), quizá para convertirse en «excepción permanente» 25 . Es un modelo, es un paradigma: la gestión política del miedo se impone. La seguridad que promete es un peligro. Para todo y para todos; pero, sobre todo, para quienes aparecen como encarnación del miedo: dan y tienen miedo, lo contraen y lo conllevan, lo concitan. Ellos, los otros: los que han venido por miedo y se han quedado con miedo; sujetos de mil temores y objetos de mil violencias. Son, claro, los inmigrantes. Expulsados de todo, propulsados a nada. Impulsados —ironía, broma- a la utopía y «repulsados» allí, aquí, donde la utopía ha dejado su lugar, y su tiempo, al miedo. El miedo traza los cursos, dicta los discursos. Sin remedio, sin recurso ${ }^{26}$.

$25 \mathrm{Si}$, como afirma CARL Schmitt «Soberano es el que decide (sobre) el estado de excepción», la cuestión de la soberanía está estrechamentre imbricada con la producción y gestión del miedo. Véase Teología política, Trotta, Madrid, 2009. Tampoco se trata -es cierto- del «auténtico estado de excepción» por el que abogaba W. Benjamin en el ya citado Sobre el concepto de historia. Y quizá sí tenga que ver con lo que A. VALDECANTos denomina, con gran acierto, La excepción permanente. O la construcción totalitaria del tiempo, Díaz \& Pons, Madrid, 2014. Para todo ello véase Saint-Bonne, F., L'état d'exception, Presses Universitaires de France, Paris, 2001. Así como las inevitables obras de G. Agamben.

26 De nuevo, y por no recurrir a una inmensa bibliografía, cito tan sólo: Wieviorka, M., El espacio del racismo, Paidós, Barcelona, 1992; Wacouant, L., Los condenados de la ciudad, Siglo XXI, Buenos Aires, 2007; Wacouant, L., Las cárceles de la miseria, Manantial, Buenos Aires, 


\section{EL OTRO}

Un sarcasmo y un ejemplo. El sarcasmo, único, lo firma Anatole France; el ejemplo es plural. Varios países europeos lo reiteran y lo matizan, añadiendo ornamento a la violencia legal(izada).

Quizá hoy no sea común, ni aun corriente, pernoctar bajo los puentes. Incluso la opción arquitectónica que representan algunos —algunos puentes—, que dificulta severamente el paso, impide decididamente el sueño. Pero, al menos para una larga época, dormir debajo de un puente fue una categoría sociológica, económica; posiblemente política y aun moral. Ahora hay cajeros automáticos resguardados, cubiertos, que reemplazan a los puentes y garantizan una suerte de pobre intimidad. No abogo por la promoción de cajeros-dormitorio. Constato un hecho.

En una de las frases más citadas de su copiosa obra, Anatole France escribía: «La ley es igual para todos, prohíbe tanto a ricos como a pobres pernoctar bajo los puentes». Era otra época, era otro París: el París de los puentes «cómodos», "acogedores». Era el París de las muchedumbres pobres o empobrecidas. Pero quizá la función de la ley no ha variado: y consienta la misma crítica, el mismo sarcasmo, que atraviesa la sentencia de Anatole France.

Parafraseando (es el ejemplo): «La ley es igual para todos, prohíbe tanto a cristianos, como a islámicos, como a ateos y agnósticos, a hombre y a mujeres, acudir a la escuela con algo que cubra su cabeza». Un punto que se ha añadido con urgencia a la normativa de los colegios prohíbe a ricos y a pobres pernoctar bajo los puentes; es decir, prohíbe a cualquier alumno acudir con prendas que cubran la cabeza. La clase aludida de prendas incluye gorras, sombreros de paja, sombreros mexicanos, txapelas, pañuelos, tocas (supongo), hiyab(s), ominosos burkas, cascos del ejército, o cascos vikingos: y otro sinfín de prendas que sería arduo constatar.

No por casualidad, el conflicto, que ya no entiende de países y de idiomas, ha surgido en el momento en el que no un rico, sino un pobre, pernocta bajo el puente. Es decir, en el momento en el que, por ejemplo, una niña islámica (islámica por su estética y por su ética, por su «cultura», acaso también por su religión) acude al colegio con una prenda, el hiyab, que cubre la cabeza y protege el cuello dejando al descubierto lo que una cursilería con cierto toque poético denomina «el óvalo de la cara».

Las leyes, en muchas ocasiones, no se hacen "por algo», sino contra algo o contra alguien. Contra álguienes.

2000; SASSEN, S., Inmigrantes y ciudadanos. De las migraciones masivas a la Europa fortaleza, Siglo XXI, Madrid, 2014; SASSEN, S., Expulsiones. Brutalidad y complejidad en la economía global, Katz, Buenos Aires/Madrid, 2015; Brown, W., Walled States, Waning Sovereignity, Zone Books, New York, 2010; Brown, W., States of Injury. Power and Freedom in late Modernity, Princeton University Press, Princeton, 2009; Vitale, E., Ius migrandi. Figuras migrantes a este lado de la cosmópolis, Melusina, Santa Cruz de Tenerife, 2006; Dal Lago, A., Non-persone. L'esclusione dei migranti in una società globale, Feltrinelli, Milano, 2004. 
Legislar no en virtud de algo sino en contra de alguien. Es cierto que ricos y pobres seguirán, prolonguemos el sarcasmo de Anatole France, disputando o compartiendo "sus» puentes (legal o ilegalmente). Pero esa suerte (desgracia) de legislación orientada, esa suerte o desgracia de contra-legislación, lo que pone en cuestión es la ley en sí misma, su estructura, su estatuto, su fundamento. Lo que pone en cuestión es el imperio de la ley. O la ley del Imperio. Y el «Estado de derecho», o el estado de los derechos.

Pues ¿qué decir de las leyes que conculcan derechos? ¿qué decir de las iniciativas políticas que pretenden distinguir entre personas según su condición? Según su origen nacional, por ejemplo. Lo que, probablemente, implique también distinguir según su raza, su color, su religión, su idioma, su posición económica. Imagen invertida, se habrá adivinado, del segundo artículo de la Declaración Universal de Derechos Humanos, de 1948, que dice: «Toda persona tiene los derechos y libertades proclamados en esta Declaración, sin distinción alguna de raza, color, sexo, idioma, religión, opinión política o de cualquier otra índole, origen nacional o social, posición económica, nacimiento o cualquier otra condición».

Alguien se hace visible, se distingue por su condición. Y su condición es la de inmigrante, la del (que ha) llegado pero no allegado, la del impertinente: por no pertenecer. Que lleva asociadas otras distinciones: una lengua materna, otra religión o ninguna, algunas costumbres «extrañas» que siempre evidenciarán su extrañeza, su extranjería: hábitos que son signo y marca de otro hábitat, que recusan su condición de genuino habitante. Está entre nosotros; pero no es uno de los nuestros. Alguien se hace visible. Se distingue. Pero esa distinción es fáctica, es meramente empírica. Veo la diferencia, la siento, la escucho en la cadencia y en el acento con los que habla «mi» idioma (dado que no voy a conceder, súbitamente y sin examen, que también es suyo). Somos diferentes, naturalmente: cada uno es cada (por lo menos) uno y cada vez es otra vez, como podría decirse con Derrida. Pero, naturalmente distintos, somos también legalmente desiguales. Diferentes ante la ley ${ }^{27}$.

Tal vez nadie haya creído que la prosa, breve y cándida, de la Declaración Universal de Derechos Humanos contuviera algo más que un propósito, o una suma de propósitos. Tal vez nunca se haya creído que la ley ignora las diferencias. Más bien, de hecho, lo contrario es cierto.

Pero hay un paso no menor entre la xenofobia de hecho y la xenofobia de derecho. $\mathrm{O}$, más insidiosamente, entre la xenomanía de derecho. E iniciativas xenomaníacas, de derecho, proliferan por doquier en la atribulada Europa. En todos los casos propuestas legales que distinguen a las personas por su lugar de origen. Y que establecen dobles, triples distinciones.

27 Diferencias legales instaladas desde antiguo y exploradas de nuevo. Véase LoRAux, N., La ciudad dividida. El olvido y la memoria de Atenas, Katz, Buenos Aires/Madrid, 2008; Loraux, N., La guerra civil en Atenas. La política entre la sombra y la utopía, Akal, Madrid, 2008; Joly, H., La question des étrangers, J. Vrin, Paris, 1992. 
Hasta hace poco tiempo acreditar la residencia era requisito suficiente para obtener la ciudadanía: no se crea, por cierto, que tal requisito era un trámite de sencillo cumplimiento. $\mathrm{O}$, al menos, no en todos los casos. Pero, al fin y al cabo, la acreditación otorgaba ciudadanía, aparentemente sin distinción de derechos.

El giro legal al que estamos asistiendo - sin oposición, por cierto, de la ciudadanía autóctona sino, más bien, con su secreta o declarada complicidad, y aun complacencia ${ }^{28}$ - radica en que en todos los casos la condición de ciudadano pasa a convertirse, para algunas personas, en un premio: que tiene un precio. Las personas implicadas son los inmigrantes. Y el precio, vagamente expresado (y la vaguedad de la expresión no es un expediente tranquilizador, sino todo lo contrario) es la «integración», que implica —más nebulosascompromiso social, voluntad de contribuir a la comunidad. Y aceptación de, y comunión con, nuestros valores.

Entre la entrada en el país y la concesión de la ciudadanía se instaura una gran zona gris, una tierra de nadie, una franja no sólo temporal para la prueba, para la vigilancia (y para el siempre insidioso castigo), para el examen. Mientras habite en ese tiempo y en este espacio, el inmigrante, diferente de hecho, es indiferente de derecho: en su condición de candidato permanece(rá) en un estado de infancia (in-fans, sin habla, semimudo, balbuciente) o de adolescencia (siempre adoleciente, siempre en falta), o de minoría de edad civil —que no penal-; en un estado que es provisional-permanente estado de excepción. ¿Qué sucederá si no apruebo el examen de idioma? ¿Qué sucederá si no apruebo el control de integración suficiente? ¿Qué si me suspenden la asignatura de valores autóctonos? Ya sabemos las respuestas. Y las preguntas, sin embargo, no son retóricas. Son desesperadamente sarcásticas.

En 1981 Michel Foucault leyó en público un pequeño texto, una declaración que luego fue publicada en el diario Liberatión. Se titulaba «Contra los gobiernos, los Derechos Humanos» ${ }^{29}$. Allí, el filósofo francés apelaba a nuestra común condición de gobernados, de personas comunes, susceptibles de abusos, de violencias, a nuestra común condición de potenciales víctimas. No una vaga solidaridad sino esa condición es la que ha de hacer pensar, hoy, en las medidas de los gobiernos: contra los Derechos Humanos.

Pues lo cierto es que a pesar de todos los discursos adversos a las retóricas de la identidad, el humano es un animal identitario. No el humano arcaico, sino también el moderno o posmoderno, el que se agita y se conmueve en los comienzos del siglo xxi de nuestro cómputo. El humano se identifica desde, con y contra su familia, su tribu, su lugar y su religión, sus costumbres y fantasías.

28 Lo que dice mucho (y nada bueno) al respecto de la democracia realmente existente. De hecho, tanto la manifestación, como la asamblea, como el referendum pueden ser (y, por desgracia, suelen ser) instrumentos de expresión y legitimación xenomaníaca.

29 Puede leerse en Foucault, M., La vida de los hombres infames, La Piqueta, Madrid, 1990, pp. 313 ss. La referencia anterior a la (in)constante vigilancia y el eventual castigo era también, obviamente, un envío a la obra del filósofo francés. 
La historia humana es, en buena parte, la transformación —escasa y lenta, o rápida y masiva - de los centros que confieren identidad o hacen de ella un problema. Y en la (in)cesante modernidad tal vez no quepa dudar de que el humano es animal racional; pero lo absolutamente indiscutible es que no ha dejado de ser animal nacional.

Por ser la identidad (individual y colectiva) una experiencia básica y radical, diferenciada y apenas consciente, las luchas identitarias se resisten a una explicación racional completa: los factores de identidad de otro individuo y de otro colectivo pueden parecerme «simples» manías, sus objetos de culto pueden parecerme meros fetiches que organizan la superstición. La modernidad pretendió acabar con la vigencia de ciertos complejos identitarios y someter las acciones y pasiones a una lógica más o menos común presidida por la razón y solicitada por ella. Sin éxito. Hoy, los centros de identificación que se constituyen en base a la pertenencia nacional y a la profesión de fe religiosa resurgen con fuerza, con la violencia de la que sólo las pasiones son capaces, y reclaman derechos en un mundo plural.

El saldo de las luchas identitarias es, en muchas ocasiones, el crimen, el asesinato sin compasión, el terror en todas sus formas. Los «viejos dioses» — de nuevo, o ya de viejo, Max Weber- reclaman, siguen reclamando, nuevos sacrificios.

El occidente posmoderno, en el que compiten cursos de conciencia y acción diferenciados, e incluso irreconciliables, se enfrenta al reto de acomodar identidades múltiples. Y es preciso asumir el reto. Es preciso asumirlo para que las retóricas de la identidad, su prosa y su poesía, sus leyendas, no sean confiscadas por los profetas del horror.

Ejemplo y argumento. El nombre de un ministerio: Inmigración e Identidad. No es una sutileza de autor, ni el título de un congreso de sociología. Es la denominación de un ministerio - existente o existido, de hecho, hace muy poco-, en Francia. La Francia orgullosa de su republicanismo que desde hace un tiempo, y con insistencia tenaz, se agita en el fragor de un debate estéril, de un debate peligroso. Que no cesa, que se incrementa y se expande por doquier.

Los medios de comunicación se hicieron eco, hace unos pocos años, de una pregunta que centra la polémica. Se trataba de la pregunta, tan presuntamente inocente como realmente insidiosa, ¿en qué consiste ser francés? La pregunta vale como paradigma. Y, donde se lee «francés» hay que poder leer "ciudadano adecaudo, convalidado, normal», más allá de la ocasional localización en Francia, que sirve, no ya como ejemplo sino como tendencia. Y, como dijo Winston Churchill, lo importante es la tendencia.

Pregunta para estudiosos y curiosos, pregunta para historiadores y antropólogos, pregunta para folcloristas. O pregunta para filósofos persuadidos por la estabilidad de las esencias y la consistencia de los fundamentos. Pregunta también para incendiar las relaciones sociales y culturales, para trazar líneas de división y de fractura, líneas de selección, de discriminación. Siempre de violencia. Y, posiblemente, de (dis)criminalización. 
Porque cuando se apunta hacia lo propio, normalmente se dispara sobre lo ajeno, sobre lo que es percibido, señalado, como ajeno. La inmigración, por ejemplo. Y ciertas formas de hablar o de amar, de rezar o de vestir, que están unidas al movimiento migratorio. Un movimiento que, efectivamente, inquieta la rutinaria estabilidad de las presuntas esencias, de las presuntuosas identidades.

Como era previsible, la pregunta imposible derivó, en su momento, en una escalada de descalificaciones: que tienen al extranjero, al inmigrante como objeto, blanco - y blanco (in)dependientemente de su color-y diana. Descubrió temores - miedos tal vez inconfesables- que los franceses comparten con el resto de sus vecinos europeos; desveló odios.

Hay quien, por ejemplo, señala al Islam, al mundo musulmán en su conjunto y en su presunta unidad, como estructuralmente no francés, como decididamente antifrancés (es más: antieuropeo, antioccidental... inhumano, bárbaro). Hay quien subraya el peligro de islamización, quien destaca el potencial de violencia que apenas se disimularía en la religión y la cultura islámicas, hay quien afirma la incompatibilidad entre el Islam y toda suerte de democracia, de igualdad.

No hay respuesta a la pregunta por lo propiamente francés (ni español, ni inglés...). No se ha elaborado una lista, imposible por otra parte, de aquellos rasgos que caracterizan la identidad gala: de aquello que hay que saber o creer, de aquello que es necesario amar y obligatorio cumplir. No se ha escrito esa lista que sería capaz de contener todo lo francés y sólo lo francés. Nada se ha firmado, nada se ha afirmado.

Eso sí: se han trazado otras líneas, se escriben otras listas. No afirmativas sino negativas. Y negadoras. La lista de las características, los rasgos y los gustos que atentan contra la indefinida identidad.

En algunos casos la lista incluye devociones. En otras afecta a formas de expresarse, o de vestir. Una ministra dijo, con seriedad, que no hay que hablar en jerga. Y que no hay que llevar la gorra al revés. De momento, parece, se trata sólo de consejos. Tal vez en algún momento ganen el estatuto legal de prohibiciones.

Pintoresco al principio, el debate logró preocupar a buena parte de los franceses. Inquieta cada vez a más europeos. La pregunta por la identidad ha fomentado la expresión de funestas pasiones, de instintos de odio y desprecio que tal vez se estén convirtiendo en rasgo o rutina de las «identidades» europeas.

Pues, se ha señalado, no se trata del «mal francés» ${ }^{30}$. La pregunta por la identidad y sus respuestas discriminadoras forma parte, cada vez más, de la

30 Quizá el ejemplo era oportuno por la publicidad alcanzada y por el rango institucional de la iniciativa. Pero "hoy mismo», (un hoy que, temo, va a durar muchos mañanas) tenemos historia y memoria (e incluso pronóstico) de iniciativas y debates similares. En Reino Unido, en España, en Luxemburgo, en Alemania, en Suiza. La lista sería larga. Como la de las iniciativas sociales y políticas de sesgo racista y xenomaníaco que se organizan 
agenda europea. Se tramita como encuesta de opinión, como debate sedicentemente intelectual, como referéndum. En todos los casos descubre su potencial de rechazo. Sustentado en opiniones y conductas que señalan al extranjero, al inmigrante, como causa de males sin fin y sin cuento. Males que se solventarían, sin duda, con la expulsión. Al fin y al cabo están aquí sin razón, sin derecho. Y, desde luego (desde ahora y desde siempre) no son de los nuestros. Nosotros tampoco.

Asombra $^{31}$ - por no escribir «asusta»- el registro en el que tiende a instalarse ese debate al respecto de la inmigración: un registro en el que predominan las consideraciones jurídicas y económicas a la vez que se minimizan, o desaparecen, todas las demás. O un registro en el que lo único importante parecen ser las cifras, los números. Sin mayores matices o mayores consideraciones. Conclusión provisional o enunciado de un problema: los inmigrantes no cuentan, los inmigrantes se cuentan. Se cuentan en los colegios y en las empresas, se cuentan en los ambulatorios, se cuentan en los juzgados y se hace estadística de su actividad legal o ilegal, se discrepa sobre el número de «irregulares». Cantidad, número, contingente, muchos, demasiados excesivos: ese es el lenguaje que habitualmente se emplea cuando de inmigración se trata.

Y es la política del número, que parte de la consideración de los inmigrantes como masa móvil, objetualizada, la que inspira otras. Por ejemplo: una política «sobre» o una política «para» la inmigración: pero no una política de, desde y con los inmigrantes. Una política que no arranque de la obsesión - que limita lo patológico- de contar inmigrantes sino de la razonable disposición a contar con ellos.

Porque algún día, entiendo, habrá que empezar a considerar a los inmigrantes, de verdad, como ciudadanos, como interlocutores: como sujetos políticos con sus propios problemas y sus propias propuestas de solución. Una política no xenófoba, o no xenomaníaca, es la que establece ese dato como punto de partida.

Una política que se libra, a la vez, de otro corolario de la obsesión numérica: la consideración de los inmigrantes en términos meramente económicos, en términos de utilidad o interés. En términos de valor de uso. Pues parecería

en partidos de creciente aceptación y éxito. Que el Mediterráneo se haya convertido en un masivo cementerio, que sea el vasto lugar de infinidad de crímenes, no es algo ajeno a esa deriva. Que miles de emigrantes, o de refugiados, pidan protección y asilo en las fronteras de Europa y encuentren indiferencia, rechazo o franca hostilidad, es un hecho: y parece marcar una tendencia. Fronteras selladas, obstáculos crecientes y una paranoia colectiva en incremento no parecen motivos suficientes para una general indignación, pero sí apuntan a una intolerable indignidad. Véase, entre muchas, importantes y urgentes consideraciones: Balibar, E., Nosotros, ¿ciudadanos de Europa?: las fronteras, el estado, el pueblo. Tecnos, Madrid, 2003; Balibar, E., Violencias, identidades y civilidad, Gedisa, Barcelona, 2005; Wallerstein, I. y Balibar, E., Raza, nación y clase, Lepala, D. L., Madrid, 1991.

31 Y el asombro, lo sabemos por Platón (Teeteto 155d) o por Aristóteles (Metafísica A 982b), está en el comienzo de la filosofía. Aunque también sabemos, por Benjamin esta vez (en las ya citadas «tesis» Sobre el concepto de historia), que no todo asombro promueve pensamiento adecuado. 
que la única justificación de la permanencia de los inmigrantes, lo único que hace que sean tolerables «entre nosotros», es precisamente ese valor de uso: el hecho de que desarrollen actividades laborales que otros rechazan, el hecho de que aporten al fisco cantidades de dinero no despreciables. No se pone en duda, claro está, la utilidad de los inmigrantes. Lo que ha de ser cuestionado, severamente cuestionado, es que el lenguaje que habla de los inmigrantes sea masivamente, si no exclusivamente, el lenguaje de la utilidad. Y no, por ejemplo, el lenguaje de la dignidad.

En una de las formulaciones de su célebre imperativo categórico establecía Kant que en cualquier situación es moralmente obligatorio tratar a toda persona siempre como fin en sí mismo y nunca como medio. Cierto es que la sociedad nunca se ha regido por tan exigente norma de conducta. Pero más cierto es que son siempre determinadas personas las que son preferentemente mediatizadas, las que son señaladas, incluso para ser defendidas, por su valor de uso. Por la utilidad que nada sabe de dignidad. Ni quiere saber.

Hay razones, muchas y serias, para preguntarse en qué código ha de inscribirse el trato con los otros, con los diferentes: con los allegados, porque llegan, impulsados por la pobreza, el hambre, o por otras formas de tiranía. Otros, diferentes: en el caso de que esas palabras tengan, realmente, alguna consistencia.

Se oye hablar aquí, entre nosotros, del diálogo entre diferentes. Se proclama o erige una diferencia que no es tal, o que es una mera exhibición de preferencias. Se prefiere hablar en una lengua o en otra, se prefiere (tal vez durante un tiempo) una opción ideológica u otra. Y a partir de esa mera preferencia se hace un elogio (o no) a la diferencia.

Pero, de repente, el diferente llega: ha llegado-no allegado. Viene y no conviene; es más, contraviene. Llega y no se sabe qué hacer con él. Pero, frecuentemente, se sabe qué hacer contra él. Se aprueba un dispositivo (i)legal: un dispositivo que ilegaliza conductas, o meras presencias. $\mathrm{O}$ un dispositivo que obliga y somete, que condena a una especie de (i)legalidad diferida, de alegalidad permanente.

La cuestión es de código. ¿Se puede, se debe, incluir en el código del derecho, en el lenguaje de la (i)legalidad, la inmigración, la diferencia, la alteridad? ¿O se ha de ensayar otra inclusión sin reclusión, sin exclusión: el idioma de la hospitalidad, por ejemplo?

Se pueden leer —es aconsejable - una infinidad de magníficos trabajos al respecto de la hospitalidad en diversas culturas. Por ejemplo, masivamente estudiado, en la griega arcaica, en la que era, la hospitalidad, una institución exigente, vinculante. Y una institución que deparaba prestigio, o público reconocimiento, a quien la ejercía, a quien se mostraba acogedor, u hospitalario. O en el ámbito judío, o en el musulmán. Otros modos, otros ritmos, otros fundamentos teóricos y prácticos, culturales, éticos, religiosos. Pero en todos los casos se trata(ba) de una actitud que tiene que ver con una exigente justicia: más allá o más acá de la ley. 
Porque la ley, la mera ley, —es una constante histórica— no obliga ni al conocimiento ni al reconocimiento del extranjero, del extraño, del «otro». De aquel que, (a)llegado o (ad)venido, se inter-pone, se pone entre nosotros. Mostrando, acaso, su desamparo y su indigencia, mostrando su dependencia. Y exigiendo, sin decir nada, sin poder decir nada, una justicia que no se agota en la ley, que no se con-forma con la ley. Una justicia supra o infralegal: fuera de la ley.

En nuestra sociedad el único código de referencia para tratar con el otro, con el denominado diferente, es el código legal, el artefacto del derecho. Ese que clasifica no ya las conductas sino a las mismas personas en legales o ilegales, regulares o irregulares. En función de unos criterios que cambian con el tiempo y las circunstancias, con las necesidades o las oportunidades. Nada, parece ser, es más lábil, más variable o voluble, que la ley que regula la inmigración. Una crisis económica, por ejemplo, hace necesario un cambio; prolonga o difiere una restricción, acentúa un sistema de exclusión. Establece una serie de líneas al interior de las cuales reina la legalidad; al exterior de las mismas se extiende el vasto páramo de la ilegalidad.

La hospitalidad es otra cosa. Es otro lenguaje, es otro código. Que se basa en la sospecha de que la justicia apenas tiene que ver con las atribuciones de la soberanía. Que se fundamenta en el hecho de que la diferencia nunca es absoluta, o de que hay una com(o)unidad profunda que protesta contra toda definición de alteridad ${ }^{32}$.

Quizá haya una justicia que ignora la ley: como hay una ley que nada sabe de justicia $^{33}$. Quizá, en esa orfandad radical, en esa exterioridad exigente - fuera de la ley- haya una oportunidad para lo que no se decide, ni se puede decidir, en un parlamento: la hospitalidad. Quizá sea ese el camino a «la perspectiva teórico-práctica de un universalismo de la diferencia que gira alrededor de la lógica de la síntesis disyuntiva ${ }^{34}$. Otro de los contenidos, apenas explorados, de la (in)cesante utopía.

U otro de los envíos pendientes de ese uni(di)versalismo que quizá late, apenas oculto, entre las torcidas líneas del relato, de la leyenda, o que se ex/pone en palabras, en argumentos, en gestos. La época democrática que nos inspira (o que nos espera) hace suya una serie - variable- de esos gestos que resisten en la historia. Cuentan entre ellos la «oración fúnebre» de Pericles bellamente transmitida - o inventada - por Tucídides, la ambigua conclusión de Aristóteles al respecto de que la democracia es el menos malo de los regímenes posibles, la declaración de independencia americana, la revolución francesa (excluyendo prudentemente la coda jacobina y la conclusión napoleónica). Y cuenta Kant: el agrimensor de la razón, el soñador insomne de la paz perpetua.

32 Importante, al menos, Derrida, J. et Dufourmantelle, A., De l'hospitalité, CalmannLévy, Paris, 1997. 2012

33 Me permito remitir a mi libro Fuera de la ley. Poder, justicia y exceso, Abada, Madrid,

34 En expresión de Marramao G., La pasión del presente. Breve léxico de la modernidadmundo, Gedisa, Barcelona, 2011, p. 15. 
Kant es uno de los pensadores más complejos (también uno de los más difíciles) que la historia recuerda. Confluyen en él las más contradictorias herencias de una época de transición. La que señala el nacimiento de nuestra modernidad.

Más avisado que muchos de sus sucesores, Kant definió al hombre por su «sociable insociabilidad». No fue fiel a la palabra de Aristóteles, ni a la de Rousseau, para los cuales la sociabilidad humana era natural. Tampoco a la de Hobbes, que no es, como se suele decir, el inventor de la «lucha de todos contra todos», pero para quien la condición natural del hombre era, inversamente, la insociabilidad.

Se agitan en Kant la herencia ilustrada - optimista, progresista, sociabilista - y la herencia protestante — el luto por la condición humana caída, la culpa sólo redimible por la gracia. Esa síntesis contradictoria provoca, necesariamente, una antropología ambigua que se percibe también en la filosofía política del filósofo alemán.

En este momento en el que la democracia debate sobre sus fundamentos y sus posibilidades, en este momento en el que la democracia muestra también sus flancos descubiertos, sus fisuras, sus incumplidas promesas, el Kant al que conviene atender es el de la «sociable insociabilidad» humana: para la que la democracia es un adecuado continente. Una comunidad de ángeles redimiría al anarquismo. Un pueblo de demonios haría bueno el despotismo (quizá ilustrado). La insociable sociabilidad hace plausible, tal vez necesaria, la democracia.

En un rincón particularmente lúcido de su vasta obra (concretamente en el parágrafo 40 de la Crítica del juicio), el filósofo Immanuel Kant hace una clasificación de «las máximas del entendimiento común humano». Tales máximas implican: pensar por sí mismo, pensar en el lugar de cualquier otro y pensar siempre de acuerdo consigo mismo (obsérvese: pensar siempre, pensar sin descanso y sin tregua, pensar en cualquier caso y en todo lugar).

Acorde con cierta Ilustración — de la que él mismo es, quizá, a la vez el mejor exponente y el mejor crítico- Kant considera que la primera máxima es la de un modo de pensar libre de prejuicios, la segunda del modo de pensar extensivo y la tercera del consecuente.

Cabe recordar la pertinencia de esas máximas y de los modos de pensar que las inspiran en este ajetreado y atribulado tiempo (y sus costumbres).

Atónitos o perplejos, escuchamos discursos que renuncian con agrado a la funesta manía de pensar. Grave cuestión, en cualquier caso. Más grave todavía cuando los discursos son proferidos (o expulsados) por líderes políticos con vocación de guías de masas o pastores de pueblos; por líderes políticos que, como el niño de Heráclito, juegan a construir y destruir castillos en la arena de la playa. Sólo que los castillos de arena son casas habitadas, pueblos y ciudades.

Los discursos a los que me refiero - los que escuchamos cotidianamente con dolor y rabia- son discursos alienados, son discursos inconsecuentes, son discursos idiotas: tanto en el sentido etimológico y erudito como en el sentido popular de la expresión. Discursos que surgen de la propia idiosincrasia, del lugar propio o apropiado, limitado y exiguo. 
Pensar desde el lugar de cualquier otro es una vacuna contra el localismo (aunque sea el localismo global del pensamiento único) y contra un universalismo vacuo e imposible. Exige la renuncia a pensar sólo desde el propio lar e implica la imposibilidad de pensar desde un inconcebible «lugar de ningún otro", desde el sitial de la divinidad.

El lugar de cualquier otro (y cualquier otro es cualquier «otro») es el lugar siempre fugitivo de la democracia, de una verdadera democracia. Un lugar permanentemente hostigado por el pensamiento alienado, por el pensamiento inconsecuente. Un lugar permanentemente asaltado por la irreductible idiotía. Ese lugar ha de permanecer descolonizado e invicto, ha de ser un lugar permanentemente impropio: nadie debe apropiarse de él, nadie debe poder apoderarse de él ni dominarlo. No domus no dominus: lugar de tránsito y encuentro sin propiedad y sin propietario, el lugar de cualquier otro es, en cierto sentido o en todos, anterior lógica y cronológicamente a cualquier (otro) lugar. Es, siempre (im)propiamente y en virtud de un argumento bastardo (lo sabemos desde antiguo), quizá lo que sin tener lugar da lugar ${ }^{35}$. Para que todos podamos visitarlo (incluso evitarlo) y salir así de las trampas que nos tiende el culto a la identidad, a la nuestra, a la propia; a la que nos constituye inevitablemente e inevitablemente nos somete y nos ciega.

\section{El Fin(AL)}

La historia enseña, si se atiende a sus instrucciones con paciencia, muchas cosas de indudable utilidad y de no escasa importancia. Cierto es que el antiguo historia magistra vitae ${ }^{36}$ fue denunciado hace tiempo como refrán de perfil conservador, que pretendía imponer a la actualidad el rigor de una herencia - a veces denominada clásica- e impedir la innovación. Los viejos odres de la antigüedad no serían, pues, capaces de contener los nuevos vinos de la modernidad. Y nuestra época, moderna y aun posmoderna, estaría orientada por la divisa de la innovación permanente, de la experimentación arriesgada, de la originalidad a cualquier precio y en pos del mayor premio: tanto las ciencias como las artes, la política o los usos sociales, se adaptan, sumisos, a ese imperativo de lo nuevo.

35 Nada se ha hecho por ocultar, más bien todo lo contrario, la referencia al Timeo de Platón. Y, sin duda, a la continua e imprescindible relectura que de ese enorme diálogo hace Derrida. Véase, al menos, DerRIDA, J., Khôra, Amorrortu Editores, Madrid, 2011. Del Timeo hay una insuperable traducción y edición a cargo de José María Zamora en Abada, Madrid, 2010.

36 Necesario remitir a los trabajos de R. Koselleck. Particularmente a: Vergangene Zukunft. Zur Semantik geschichtlicher Zeiten, Suhrkamp, Frankfurt a.M., 1979; Zeitschichten. Studien zur Historik, Suhrkamp, Frankfurt a.M., 2003; Begriffsgeschichten, Suhrkamp, Frankfurt a.M., 2006; Vom Sinn und Unsinn der Geschichte, Suhrkamp, Frankfurt na.M., 2013. 
Para los tiempos y los modos que nos instruyen, para las citas pendientes y los ajetreos consecuentes, hay una instrucción que se puede extraer al considerar un esquema vigente en (o desde) los viejos tiempos del profetismo hebraico, o en la época intertestamentaria; un esquema que se reitera en los primeros tiempos del cristianismo (sobre todo en ambientes paulinos y joánicos) y que ha acompañado a Occidente en su historia hasta los mismos umbrales de la modernidad. La instrucción, en su fórmula más simple, diría: en política, como en otras cuestiones acaso más importantes, es preciso contar con el tiempo, pero es peligroso anticipar el fin; y mucho más peligroso poner fecha al fin.

Y es que desde las experiencias, traumáticas, del exilio judío, la predicación profética fue acentuando la conciencia mesiánica y su dimensión apocalíptica. Con ellas la dedicación a escrutar los tiempos y los signos de los tiempos. Con la mirada puesta en el fin.

Otro tanto sucedió tras la muerte y resurrección de Cristo. En muchos ambientes el tiempo que resta (sintagma decisivo en la carta de San Pablo a los Romanos, y no sólo en ella) se percibió desde la perspectiva de la inminencia, y, por ello, con el complemento de la urgencia.

Y esa ha sido la constante histórica, que volvió a reiterar su pauta en la frontera del primer milenio. Y que lo hizo de nuevo, y ya para asumir una vertiente netamente política, tras la Reforma protestante y las ulteriores guerras y revoluciones. Cuando eclosionó, por cierto, la prosa —un punto poética, otro punto patética- de la utopía: otra — ¿o la misma? - gestión del tiempo (y) del fin.

Duramente incorporada, la lección histórica de tantas especulaciones sobre el fin de los tiempos, o la voluntad, ya secularizada, de poner fin y término (Ziel y Ende) a todos los procesos, no ha sido del todo aprendida. Es más, en algún momento (que puede o suele coincidir con el «momento moderno») la especulación sobre el fin se con-fundió y se complicó con un renovado entusiasmo dirigido hacia un fin (Ende) que era meta (Ziel), un renovado entusiasmo con la vista orientada hacia el fin(al) de la historia. Un fin(al) en el que la política y lo político quedaban atrapados: sujetos, en todos los sentidos del término. Y todavía se oyen cánticos que convocan a la «lucha final», o a toda una suerte de persecuciones y/o postergaciones de fines finales. Eso sí, parece que ahora la fecha queda en suspenso ${ }^{37}$.

Si algo tiene que haber aprendido la democracia en su breve y traumática historia es que precisamente ella, la democracia, es ciertamente un tipo de gobierno sobre espacios y territorios, y sobre personas, que tiene determinadas características institucionales y determinadas garantías legales. Pero que es un gobierno en el tiempo y del tiempo, no un gobierno del fin(al).

Cada época, cada forma de pensamiento y acción, elige sus héroes y sus mártires, edifica un panteón acorde con sus necesidades. Y transforma ese panteón a medida que esas necesidades cambian.

37 Para algunas consideraciones al respecto de todo ello me permito citar mi libro Orden sagrado, santa violencia. Teo-tecnologías políticas, Abada Editores, Madrid, 2014. 
Hay, efectivamente, un «tiempo de la democracia» que no es asimilable al de otros sistemas de dominación, o al de otros sistemas de gobierno. El tiempo de la democracia es el tiempo de las decisiones consensuadas y pactadas ${ }^{38}$, o de los conflictos explícitos y encauzados, o de las decisiones basadas en la fuerza de las mayorías..., o, no nos engañemos, en la mayor fuerza de potentes minorías. Ciertamente asentadas en «principios» y sin duda orientadas por «fines» (ambos en plural) ${ }^{39}$. Pero el tiempo de la democracia mantiene a distancia la expectativa del fin: del fin(al) de los tiempos ${ }^{40}$. Tanto en términos absolutos como en términos relativos. El fin(al) que conduce o gobierna los tiempos y los procesos produce irritaciones y urgencias - o ralentizaciones y cautelas- que, en el extremo, se llevan mal con los procedimientos democráticos de decisión.

Cuando se gobierna - o cuando se piensa - con la vista puesta en el fin(al), sólo cabe la política del «o lo uno o lo otro», sólo cabe la política de la dicotomía pura, de la contracción de alternativas: o del puro enfrentamiento polémico sin mediación propiamente política. Sólo cabe el «nosotros» o «ellos», sólo cabe la designación del otro como adversario en el grado máximo: como enemigo. Y, de nuevo, tanto la historia como la teoría suministran ejemplos; y argumentos.

Un filósofo y un dramaturgo del extremo septentrional de Europa nos colocan permanentemente ante el planteamiento de un dilema sin mediación posible, ante la expresión de un conflicto cuya solución no admite grados: suma cero, se gana todo o se pierde todo. Kierkegaard e Ibsen, penetrados por la herencia de Lutero, son autores de sentencias cuya radicalidad asusta: «o lo uno, o lo otro» dice el filósofo, el «pensador religioso» que fue Kierkegaard; «o todo, o nada», repite Brand, el pastor, el profeta, uno de los personajes más logrados de la dramaturgia ibseniana.

El problema de ambos, el de Kierkegaard y el de Brand, es el de la salvación. La salvación del alma, del individual concreto, del hombre/mujer «que somos tú y yo».

38 Pero, sin duda alguna, no en una «situación ideal de diálogo», como propondría Habermas, sino en diversas situaciones reales de confrontación.

39 Asentadas en «principios» y orientadas por «fine» que suelen componer la cálidad prosa de la constitución formal (es decir, de la Constitución, con mayúscula inicial). Pero también atravesadas o nutridas por interesaes, pasiones y ambiciones. Confesables e inconfesables.

40 Ni fin(al) de los tiempos, ni fin(al) de la historia, ni toda la cohorte de (re)acciones asociadas a esos fin(al)es. Sí, sin duda, la apertura, o el darse al darse de un fin sin final previsible, sin final calculable. A un fin incalculable, ajeno a toda y cada economía. Un fin incontable con el que hay que contar. Tal vez lo que algunos denominan acontecimiento; $\mathrm{y}$, en cualquier caso, irrupción, interrupción. Quizá la democracia (por venir, como diría Derrida) sea (im)precisamente esa apertura sin seguridad, esa donación sin reservas, esa entrega sin futuro. Ese cuento sin cuenta. Ese eso por venir. Al respecto del fin(al) es importante el artículo de Antonio Valdecantos, "La demora de la ambigüedad. Notas sobre escatología, historia y ambivalencia», en Pardos, J. (ed.), Historia y catástrofe, Cuaderno Gris, Madrid, 2012, pp. 207 ss; y el libro del mismo autor, Antonio Valdecantos, Filosofía de la caducidad, Plaza y Valdés, Madrid, 2015, en el que el citado artículo cobra mayor envergadura y se expone en un muy adecuado contexto argumental. 
Esa forma de pensar la religión, esa eliminación sistemática de las mediaciones, esa hostilidad a los pactos y a las «medias tintas» produce una peligrosa fascinación y se propone como estructura para el planteamiento de cualquier conflicto.

Es, sin embargo, una forma plana e insuficiente: si se utiliza para resolver el conflicto que cada individuo es, conduce al suicidio. Tampoco sirve para plantear el conflicto sentimental, o el conflicto familiar. Y tampoco es aconsejable para abordar los conflictos sociales y políticos.

La política - es oportuno convocar la vieja sugerencia- es el arte de lo posible. Es un arte: ni ciencia ni religión. Es un arte ${ }^{41}$ : no tiene nada que ver ni con la exactitud que la ciencia pretende ni con el/lo absoluto que la religión persigue y anhela. La política tiene que ver con artefactos y artificios. Con instrumentos fabricados para posibilitar el grado más alto posible de convivencia y cooperación.

Los artefactos, los artificios políticos son - en estos tiempos- fruto de la discusión y del pacto; frutos híbridos en los que se sintetizan intereses y voluntades, horizontes y espectativas.

En el ámbito de lo político no es oportuno —ni inteligente- decretar la muerte de «algo»: de un artefacto, de un instrumento. Es conveniente elaborar mediaciones y recelar del «o todo, o nada», de la venenosa fascinación de la suma cero.

En 1598, hace cuatrocientos (y pico) años, Enrique IV, «rey de Francia y de Navarra por la gracia de Dios» firmaba el famoso edicto de Nantes, con el que se intentaba articular la convivencia civil entre católicos y protestantes. La historia reciente descubre en el mencionado - y pronto derogado- edicto uno de los principales hitos en la accidentada conquista de la tolerancia como clave de bóveda de la pacífica coexistencia de los humanos.

El episodio de Nantes había sido precedido por otros intentos de restaurar la paz entre las aludidas confesiones religiosas. Intentos frustrados, que no fueron capaces de detener un proceso de variables hegemonías, mutuas agresiones y sangrientas guerras.

Seguros de sus convicciones, severos en sus argumentos, los principales líderes tanto católicos como reformados, se opusieron drásticamente a cualquier ensayo de concordia. Más detestables incluso que los miembros del bando opuesto fueron considerados los «mediadores», aquellos que proponían un diálogo que propiciara el acercamiento de posturas y la consecución de la paz civil.

Fue Calvino el que, en este contexto, comenzó a utilizar el término mediator (el latín era todavía la lengua franca para la intercomunicación cultural) de forma peyorativa. En el momento crucial de la lucha entre los varios dogmatismos

41 Arte en el viejo sentido de la latina ars, o de la griega téchne. Porque, como se verá en breve, hay artes... más (o menos) electivamente afines con la política que tal vez no sean del todo aconsejables. Y, por otra parte, teorías y prácticas de estetización de la política resultan conocidas. Y funestas. 
el ensayo de mediación era percibido como traición, como deserción de la verdad celosamente defendida y violentamente impuesta.

La seña de identidad de todos los totalitarismos es precisamente la proscripción de toda discrepancia, la persecución de todo aquello que se desvíe de la ortodoxia inventada y resueltamente impuesta. Cuando, en la época de la Reforma, combatían entre sí los dogmatismos, el mediator — doblemente sospechoso, doblemente infame- apareció como candidato unánime a la hoguera.

$¿$ ¿Ha enseñado algo el paso del tiempo? ¿Han dejado su poso los siglos transcurridos? El presente es de nuevo arisco, proclive a los dogmatismos de vario signo, celoso de inciertas certidumbres. El intento de proponer mediaciones, de articular las varias sensibilidades en el territorio común de una civilidad compartida, recibe hoy el mismo desprecio, la misma sanción negativa que Calvino y el Papa de Roma inauguraran hace cuatro siglos.

Cabe pensar, sin embargo, que el denostado mediator ${ }^{42}$ sea, en su actitud, el portavoz autorizado de la anhelada tolerancia y del pluralismo asumido como forma de vida. Lo otro, lo mismo, lo de (casi) siempre es... otro arte.

Y por amor al arte, a ese arte, se escribieron, y perduran, algunas de las obras que mejor nos informan al respecto de la humana condición. Por amor al arte... de la guerra.

El arte de la guerra ${ }^{43}$ es el título con el que se conoce un texto precioso e imperecedero. Atribuido a Sun Tzu, personaje tal vez imaginario, tal vez colectivo, es un documento que data de la "época de los reinos combatientes», y fue escrito en algún momento -indeterminable- entre los años 400 y 320 antes del comienzo de la Era Común (es decir: hegemónica). La obra de Sun Tzu es un manual de estrategia, de teoría política. Y un estudio antropológico.

Con otro estilo, con otro propósito, la primera obra de la tradición literaria de Occidente se escribió con amor al mismo arte, a la misma guerra. Atribuida a Homero, personaje tal vez imaginario, tal vez colectivo, La Iliada es el largo - y espléndido - relato de un acoso. Esa guerra y su historia permanecen ligadas a nuestro imaginario colectivo. Y muchas otras veces, en la realidad o en la ficción, en la literatura o en el cine, las mismas musas han ayudado a cantar la cólera de otro Aquiles.

Parece un destino que algunas de las primeras aplicaciones de la escritura se consagraran al arte de la guerra. Que su origen se difumine en la alborada del texto y el autor sea una sombra, un nombre: no un hombre. Tal vez eso indique

42 Esa figura, denostada antaño, del mediator no se requiere ahora, o aquí, como actor para un vago consenso, o como protagonista de una "gobernanza global» con perfiles cada vez más hoscos y realizaciones cada vez más delincuentes. Se reclama como figura crítica, hipercrítica, deconstructiva, desenmascaradora de seguridades, consensos, gobernanzas..., es decir, de todos los dogmatismos de nuevo cuño.

43 Sun Tzu, El arte de la guerra, Fundamentos, Madrid, 1990. Pero ha de verse también un documento excepcional, The Book of Lord Shang, del que hay una excelente edición debida a J.J.L. Duyvendak y reeditada en Chicago University Press, Chicago, 1963. 
que la guerra es patrimonio común del humano; que Sun Tzu y Homero son el nombre de todos, o de algunos que han escrito lo que todos han realizado.

No sé si la historia humana es historia de las culturas, o historia de las técnicas. Sospecho que es, incesantemente, ininterrumpidamente, historia de las guerras. El pasado siglo veinte se entregó a ellas con dedicación ejemplar. Tanto la historia como la leyenda de ese siglo, son la larga memoria de guerras atroces.

El siglo que nos contiene parecía prometer otros hechos y otros relatos. Pero, tal vez porque la creatividad tiene sus límites, se vuelve a entregar al arte, a ese arte imperecedero. Esta vez con ingentes inversiones económicas, con sofisticadas investigaciones tecnológicas, con la proyección al futuro del miedo y de la inseguridad.

Quizá sea cierto, desde los tiempos de Homero, que los dioses siembran la discordia entre los hombres: por amor al relato, por amor al arte. Y, tal vez, a la política.

Carl von Clausewitz ${ }^{44}$, lapidariamente, afirmó que la guerra es la política continuada por otros medios. Clausewitz era un especialista en la guerra y casi un extranjero en la política. Politólogos de varias ideologías optaron pronto por invertir la frase del militar germano continuando su lógica: la política sería entonces la prolongación de la guerra. Con otros medios.

Efectivamente, la vida en común, una de cuyas especificaciones es lo políti$\mathrm{co}$, es terreno de tensiones y antagonismos, es terreno en el que se libra permanente batalla con y contra los otros, con y contra el entorno. Se puede aceptar que la lógica agonal de la guerra se confunde con la estructura básica de lo político. Y entonces la coda de la citada frase gana en interés.

La guerra establece relaciones inmediatas, relaciones somáticas, tanto entre los amigos como entre estos y los enemigos ${ }^{45}$. En la guerra el conflicto se escenifica en su forma primaria, manifiestamente corporal; en la guerra rige sólo la lógica que Carl Schmitt quiso extender a todo el ámbito de lo político ${ }^{46}$. Sólo hay amigos y enemigos. Y entre ellos el conflicto es radical, literal y destructivo: en el extremo, sin cuartel y sin tregua.

El ámbito de lo político escapa —o debe escapar - de la literalidad y el somatismo. Tal vez su cometido sea aceptar y asumir el conflicto, latente o

44 Von Clausewitz, C., Vom Kriege, Weltbild Verlag, Ausburg, 1990. Ha de verse al respecto Aron, R., Penser la guerre: Clausewitz. Vol I: L'âge européen; Vol. 2: L'âge planétaire, Gallimard, Paris, 2009. Quizá la más conocida inversion de la frase de Clausewitz sea la que realiza, reiteradamente, Michel Foucault. Pero la tendencia de pensar (o no) la política como la guerra proseguida por otros medios data de mucho antes. Véase, por ejemplo, RosenzweIG, F., «La meta de la guerra» en: Escritos sobre la guerra (edición de Roberto Navarrete), Ed. Sígueme, Salamanca, 2015, pp. 91 ss.: el texto en cuestión se escribió en 1917.

$45 \mathrm{Y}$ esto es cierto incluso en las guerras actuales, tecnológicamente sofisticadas y sólo aparentemente «incorpóreas».

46 Además de las obras citadas es necesario volver a insistir en el libro clásico Der Begriff des Politischen, Duncker \& Humblot. Berlín 1996. 
patente, y ritualizarlo: establecer mediaciones que den cabida a la confrontación sin que esta llegue a su ápice destructivo.

No es política - aunque pretenda, con éxito, ese nombre- la actividad que permanece en el plano literal, la que sólo entiende el conflicto en su forma violenta de expresión; no es política la actividad que divide el espacio social entre amigos y enemigos sin establecer distancias, matices y mediaciones.

La lógica subyacente es común a la política y a la guerra. Los medios establecen la diferencia entre una y otra. La lógica subyacente es común a casi la totalidad de las relaciones humanas: que se edifican sobre la tensión y el conflicto, incluso en el interior de uno mismo, de cada conciencia, infeliz y desgarrada. La diferencia está en los medios. Quizá de eso se trate, de principio a fin. De medios sin fin(al).

En la frase de Clausewitz, en todas sus postreras versiones, cabe - para no llamarse a engaño- considerar y apreciar la relación que se establece, la familiaridad que se afirma. Y cabe subrayar: por otros medios.

$$
* * *
$$

Cuando se gobierna con una orientación al fin(al) el tiempo se distiende: y caben en él multitud de procesos diferentes, multitud de alternativas, de dilaciones, de demoras y desvíos. Cuando se gobierna con otra orientación al fin(al) el tiempo se contrae: y, en el extremo, ya no hay tiempo, no hay procesos, no hay gobierno.

Eso parece suceder en las atribuladas democracias occidentales que, huérfanas de principios y cada vez más vacías de contenidos, coquetean con el fin(al): de la modernidad y del Estado de Bienestar, o de una sociedad que había apostado al futuro toda su fortuna y a la que la actual crisis ${ }^{47}$ golpea en sus fundamentos. No es que no haya futuro, sino que el futuro, ya no feliz, insinúa los rasgos de la tragedia. O deja oír si no las trompetas del apocalipsis, sí las estridencias del miedo. Y sus funestas consecuencias.

Injertado el fin(al) en la sociedad y en las políticas y canceladas sus ajadas promesas, se incorporan con-y-sin-él todas las urgencias, todos los miedos, todos los peligros, todas las demoras, todos los desv(ar)íos. Y muchas violencias. Injertado el fin(al), el tronco político se pudre. Y en los márgenes - esos márgenes proliferan por doquier, se multiplican sin descanso- hay quien sufre la violencia de la exclusión, la violencia de la expulsión. La violencia; legal, letal.

Universidad de Deusto (Bilbao)

Patxi Lanceros

patxi.lanceros@deusto.es

[Artículo aprobado para publicación en diciembre de 2015]

47 Ya se ha indicado que la palabra es inadecuada, o altamente ideológica. «Coyuntura» o «estructura» serían expresiones más correctas. 